\title{
Analysis of incremental die bending of wires and tubes
}

\author{
Viktor Holstein ${ }^{1}$ Matthias Hermes ${ }^{1}$ - A. Erman Tekkaya ${ }^{2}$
}

Received: 23 August 2019 / Accepted: 21 January 2020 / Published online: 29 January 2020

(c) The Author(s) 2020

\begin{abstract}
The use of bent wires, tubes, and profiles has a broad application in the industry as it is based on a great number of possible applications. Both structures with a high light-weight construction potential as well as functional and aesthetic geometry can be realised expediently. Known processes are often limited in case of tight radii and complex bending contours that cut each other or that are similar to a loop. The so called incremental die bending provides the remedy. It is an innovative process for the production of complexly shaped workpieces in the form of bent wires, tubes, or profiles. The bending process in case of incremental die bending is different to conventional processes, since a die is reshaped. With this process the semi-product is put into a hard bending shape by a moving feeding unit. The process is very accurate and at the same time cost-effective, since almost any bending contours can be produced form-based in one working stage. Furthermore, the die geometry enables the manufacture of contours that were previously very work-intensive or not producible at all.
\end{abstract}

Keywords Bending $\cdot$ Incremental die bending $\cdot$ New bending process

\section{Introduction/state of the art}

Incremental processes are one of the most efficient manufacturing processes, especially for small quantities, but these processes are often very slow and not suitable for larger quantities. For this reason, tool-bound processes are increasingly being used in practice. The topic of this paper is a novel process from the group of incremental processes that generates complex shaped profile-based components.

In the field of profile bending, rotary draw bending, threeroll bending, and stretch bending are common methods. The three-roll bending is the most flexible process and has the largest range of possible geometries. The kinematic adjustment of the rolling and the feed unit, allow various bending lines to be produced with only one tool set. In case of circular cross sections, 3D bending contours are possible. However, process control and precalculation is still strongly

Viktor Holstein

holstein.viktor@fh-swf.de

Matthias Hermes

hermes.matthias@fh-swf.de

A. Erman Tekkaya

Erman.Tekkaya@iul.tu-dortmund.de

1 Fachhochschule Südwestfalen, Iserlohn, Germany

2 Technische Universität Dortmund, Dortmund, Germany based on the trial and error method and is suitable for larger bending radii. Nevertheless, there are recent approaches, see [1], to calculate bending contours analytically in advance and thus to minimise the number of trial runs drastically.

Currently, the rotary draw bending (RDB) is chosen in the context of tight bending radii and thin wall thickness [2]. It was investigated extensively; in particular the wrinkling is presented by $\mathrm{He}$ et al. [3] in a detailed study on the influence of important parameters. There are also analytical approaches that describe the process, e.g. Engel et al. [4] presenting the calculation of the necessary bending moment for the rotary draw bending. RDB enables high quality bends. With circular profiles, even 3D geometries can be produced. The reason is the good supporting and guiding of the profile cross section during the bending by the tools. However, a new tool set is needed for every profile cross section and bending radius. Furthermore, a machine with several tool levels is necessary for the various bending radii. For this purpose, rotary draw bending is combined with the three-roll bending, since both can be implemented on the same machine tool.

Stretch bending is a high-precision bending method. By a superposition of tensile stress, the springback can actively be minimised and the forming result can be improved, which is necessary for asymmetrical profiles [5]. The low springback allows the bending of very complex cross-sections. 
However, even with $2 \mathrm{D}$ bends, the remaining springback must be provided by twisting the bending form. This results in an elaborate preparation phase due to some trail and error attempts. This leads to the fact that currently more research is being done to shorten this phase by FEM simulations or analytical approaches. Liu et al. [6] developed an analytical and FEM approach for stretch bending of $\mathrm{Z}$ and $\mathrm{T}$ profiles. He showed also the influence of different FEM-parameters on the result and the computation time. Zhao et al. [7] developed an analytical model too, thus presented an approach which also applies to variable cross sections. Another possibility to minimize springback and to form harder materials is the hot stretch bending. Through an additional heating unit, materials difficult to form such as titanium alloys have a good workability [8]. Stretch bending, however, is restricted in its degree of freedom and enables only large bending radii [9]. Machine costs are also significantly higher than with RDB or three-roll bending.

In recent years, the high flexibility of the kinematic bending process has led to the development of further freeform bending processes. Noteworthy are the "freeform bending with movable die" [10], the "multiple-roll bending combined with torsion" [11], or the Hexabend procedure [12], according to VDI 3430. All three processes have high flexibility at the bending geometries. However, the collision with the tools or machine components, overlaps, tight radii, and tension superposition are not possible with these procedures.

The large number of bending processes as well as their intensive investigation and further development show that there is still a great need for processes that allow even more complex geometries for both large and small quantities. Another goal is a robust and reliable process that is currently only achieved by form-based bending processes. Incremental profile bending offers an efficient possibility to realize curved profiles in the accuracy of shape-bound processes even for small quantities. Although the process is not as flexible as kinematic bending processes, the effort required for a bending form or segmental support is very low (Fig. 1c), especially because the groove can be produced in the same machine where the wire is bent. The incremental die bending process combines the efficient of free-form bending and the reliability of form-based bending processes. The method allows geometries that can hardly be produced with other processes. In addition, it is suitable for both small and large quantities due to the simple and cost-effective design. In the following, the basic idea of the procedure will be presented and first results of the investigations will be discussed.

\section{The process idea}

The fundamental idea of incremental die bending [13], is to insert a round bar, tube, or profile through a moveable forming device into a die or a die system form with segmental support, see Fig. 1. At the beginning of the process the profile is to be fixed in a clamping device. The bent part is created by the movement of the forming device along the groove of the die and the synchronous feeding of the profile into the groove.

Additionally the feed unit enables active axial tracking or even the superposition of tensile or compressive forces in the longitudinal axis of the profile. The superimposition can be achieved by slowing or accelerating the profile feed. Thus, the forming device enables the superposition of tensile stress or compressive stress in the bending process. By twisting the forming device around the longitudinal axis, an additional torsional stress can be superposed.

The bending geometry is given by the tool design. This either consists of a groove-line design (Fig. 1a) or of segments (Fig. 1c). A heating device can additionally be integrated for the forming of larger cross sections or

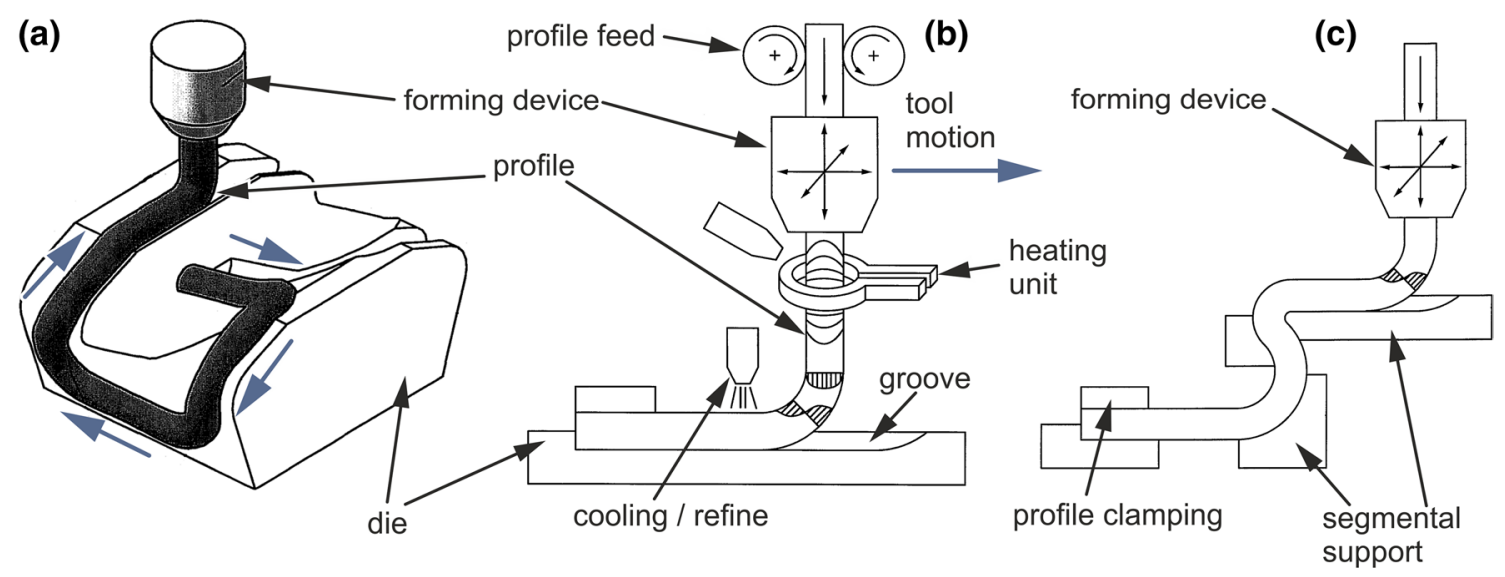

Fig. 1 Principle of incremental die bending 
high-strength materials, see Fig. 1b. With a subsequent targeted cooling, it is possible to temper the profile.

This new bending process, the incremental die bending, has advantages over previous manufacturing processes. Almost any geometry can be produced with high accuracy and complexity by form-based bending. Geometries that have the form of a loop can be bent collision free and without an interstage. With an additional stress superposition, the bending can be specifically influenced, which is similar to stretch bending. The low tool costs result from the production of the workpieces in only one station. The die groove can be machined on the forming machine by mounting a milling tool instead of the forming tool. Thus, this process has high potential in particular for the production of prototypes and smaller production-lots. The process is very robust so a high feed speed can be adjusted. During the experiments speeds of $1000 \mathrm{~mm} / \mathrm{min}$ were used. Because of the high speed of the feed unit during the bending, there is the possibility to implement larger production-lots. The process can be applied to all formable materials.

\section{Experimental setup and FE model}

An experimental setup and a FE model for the process were built during the investigations. A groove was milled in a die with a conventional CNC milling machine that corresponds with the planned bending geometry for the tests. Subsequently, the milling cutter was replaced by the forming device. With this device an aluminium wire (diameter $5 \mathrm{~mm}, \mathrm{Al}$ 99,5 and EN AW 6060) was formed into the tool, see Fig. 2. The die was installed on a multi-component dynamometer so that the forming forces of the procedure could be recorded in $\mathrm{X}, \mathrm{Y}$, and $\mathrm{Z}$ directions.
The results of the first experiments achieved a high level of bending accuracy and showed only a slight springback. Furthermore, the process enabled the bending of a profile with a circular cross section (diameter $4.75 \mathrm{~mm}$, wall thickness $0,7 \mathrm{~mm}$, copper-nickel alloy) with the same geometry, see Fig. 2 on the bottom right. The feed velocity of the CNC mill was $1000 \mathrm{~mm} / \mathrm{min}$ during all experiments. Higher feeds are possible without reaching process limits here. In addition to the experiments, a numerical model of the process was developed. The model was built up with the FEM software Abaqus, see Fig. 3 on the left. Rigid body elements were used for the tool elements, for the aluminium profile there was used a 3D volume element (C3D8R). The friction between the profile and the tool elements was calculated using the Penalty method and a friction coefficient $\mu$ of 0.1 . The flow curve was determined using a tensile test and according the approach of Ludwik, see Fig. 3 on the right.

\section{Correction of the tool path}

To generate components of high-quality with the incremental die bending process, a kinematic correction model and a path planning tool were developed. This is necessary, because the path of the forming device does not follow the geometry of the die groove. The distance arises by the offset between the middle axis of the forming device and the forming zone of the process, see Fig. 4 (offset $X$ ). The forming zone is the area where the profile comes into contact with the top level of the die. The offset depends on the radius of the forming device and the diameter of the wire. It must be adjusted to the radius area of the die, see Fig. 4 on the right side. If this is disregarded at the path of the forming device, the profile won't be inserted correctly into the groove. Thus,

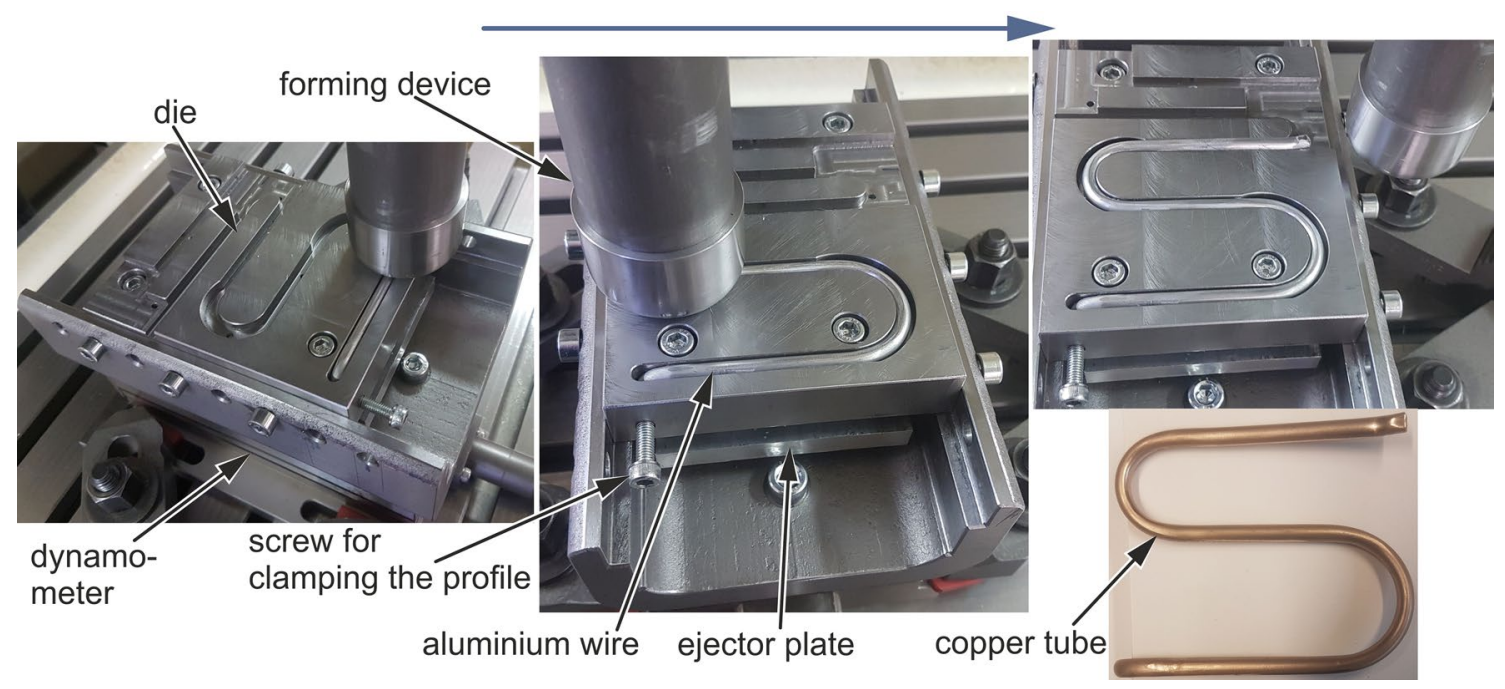

Fig. 2 Experimental test bench 


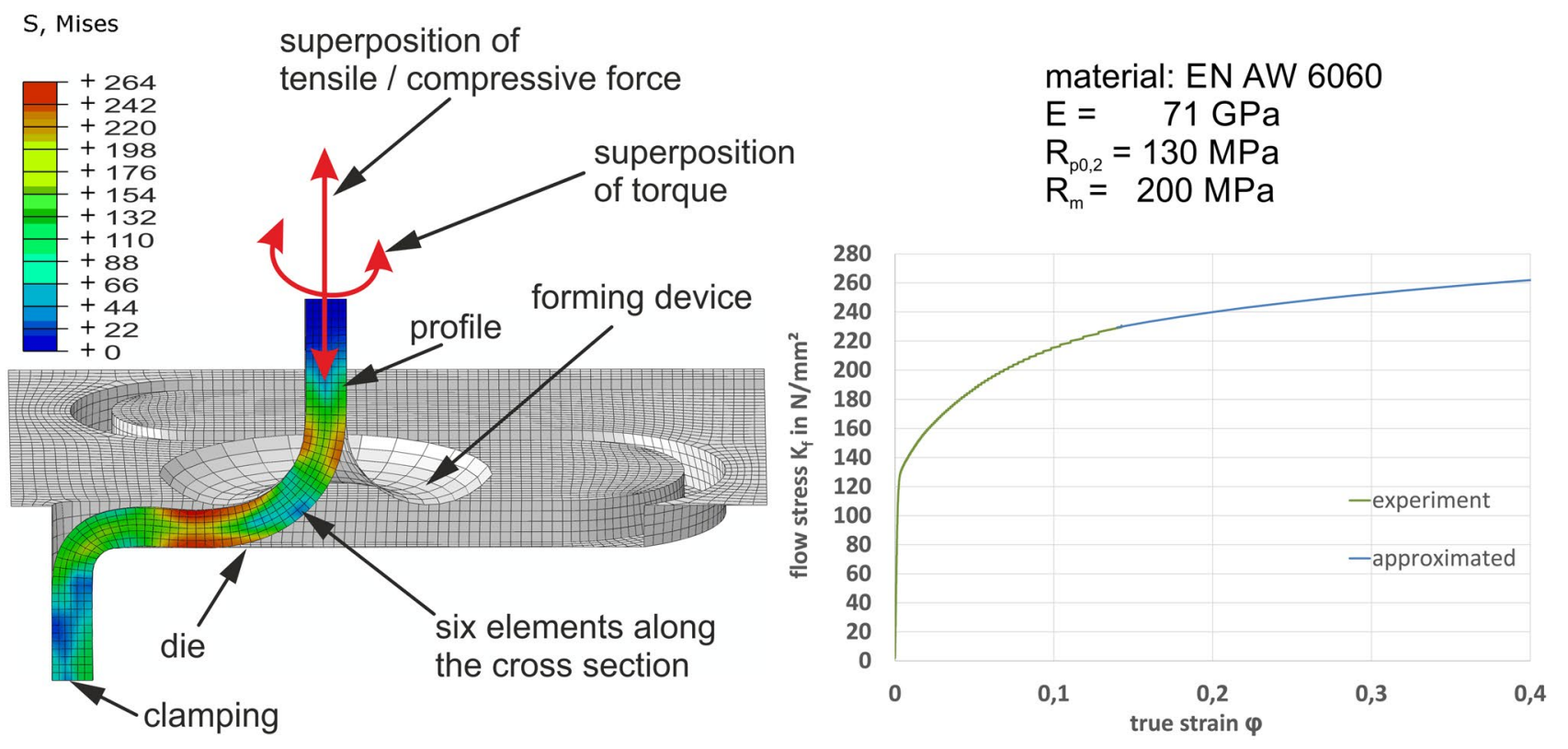

Fig. 3 FE model and flow curve

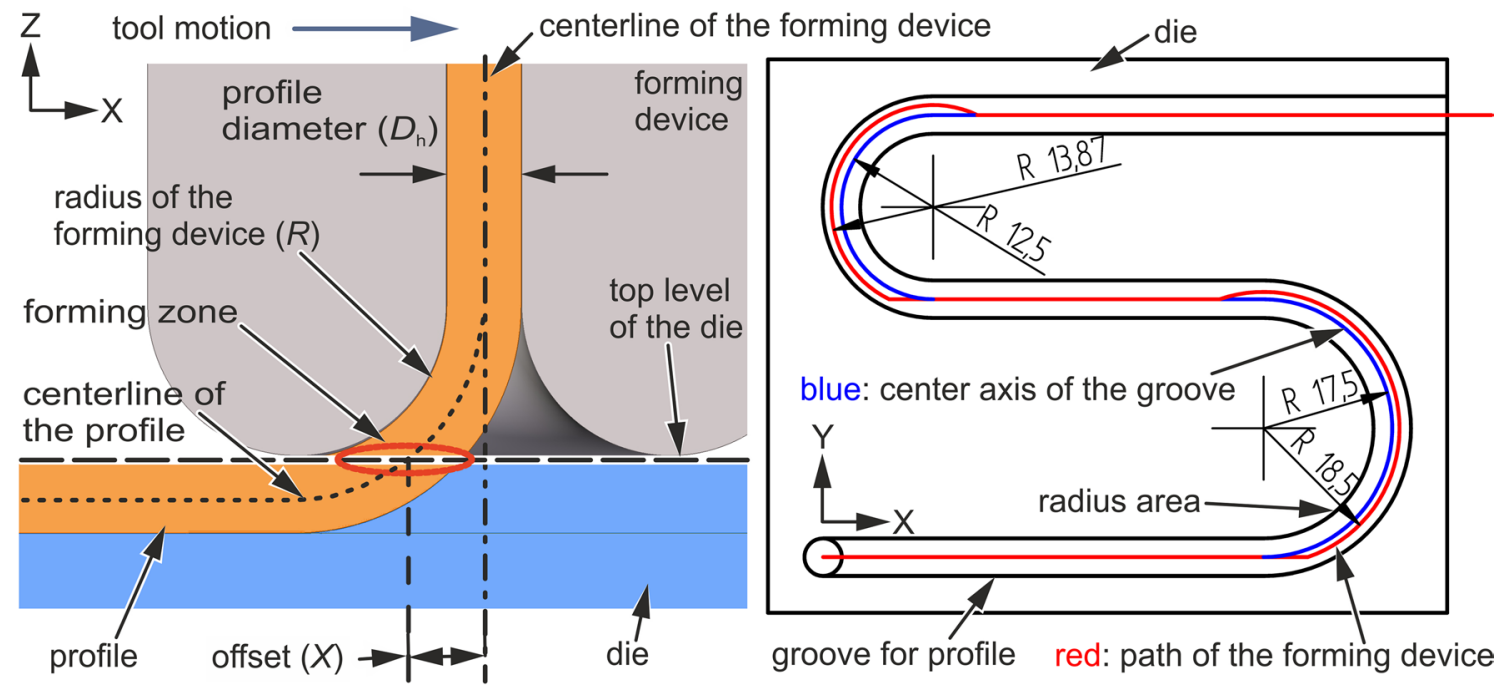

Fig. 4 Forming zone/path correction

this would lead to a high deformation of the cross section and in some cases even to a rupture of the profile in the arches, see Fig. 5. Due to the special conditions of the process, it was necessary to adjust the kinematics of the path for the forming device.

The offset of the forming zone can be calculated mathematically for profiles with a symmetric cross section. Using the diameter of the semi-product $\left(D_{h}\right)$, the diameter of the forming device $\left(D_{f}\right)$, and the extrusion radius of the forming device $(R)$, the setoff $(X)$ can be calculated by the following equation:
$X=\left(R+\frac{D_{f}}{2}\right)-\sqrt{\left(R+\frac{D_{h}}{2}\right)^{2}-R^{2}}$

The calculated offset $X$ could be verified successfully by experiments and the FEM. However, the stiffness of the forming device had to be considered for the practical tests. In doing so, further components were added to the formula: 
Fig. 5 Forming on the left without and on the right with path correction
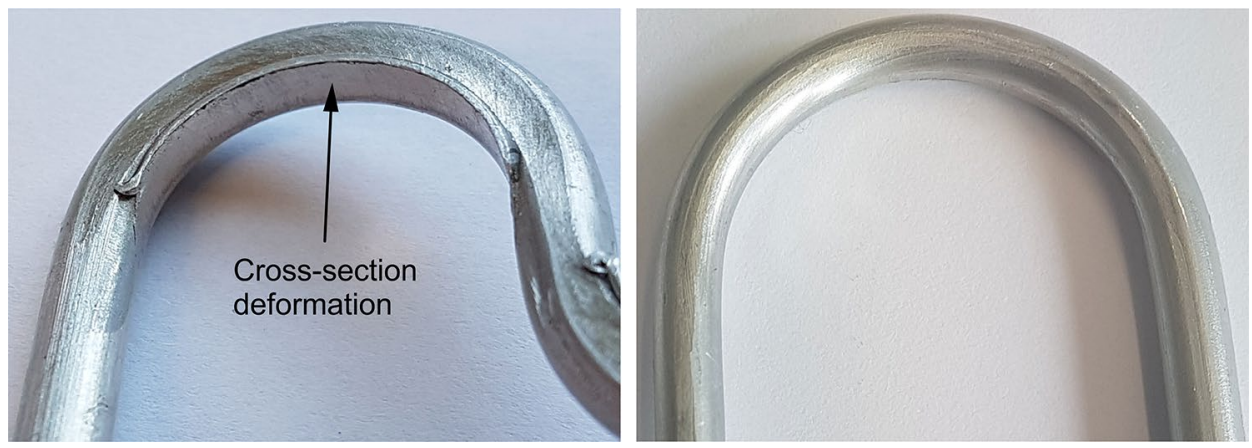

$X=\left(R+\frac{D_{f}}{2}\right)-\sqrt{\left(R+\frac{D_{h}}{2}\right)^{2}-R^{2}}+X_{c}$

$X_{c}$ depends on the stiffness of the guiding unit. The stiffer the forming device and the smaller the forming forces (softer material), the smaller is the value. The path correction had in all experiments a crucial influence on the results and was used for all tests. The calculated offset $X$ must be mainly considered in the curves, see Fig. 4 on the right. By adjusting the starting and endpoints of the circular path and the radius, the displacement of the forming zone is balanced and the profile is inserted correctly into the groove.

Furthermore, an independent tool has been developed for the path correction that enables the correction in an automated manner. This could be tested successfully on several geometries. The Archimedean loop was a particular challenge, since it has a continuous decreasing radius, see Fig. 6. There could be calculated a corrected path kinematic with the tool and subsequently the component could be bent successfully. Using the tool enables to describe the path similar to DIN 66025/ISO 6983 or to implement the points directly into the tool (X, Y, Z-coordinates). By indicating the dimensions of the bending head and the desired feed (rate) a corrected path can be calculated for the CNC milling machine and another one for the FEM software.

The understanding and calculation of the displacement of the forming zone was essential for the practical implementation of the process. This avoided a blind approach to the contour and the number of trial runs could be drastically reduced. By accumulating some experience for the different materials and diameters, those could be reduced to almost zero. The software tool even allowed an implementation for complex geometries with a constantly changing radius.

\section{Analytical model}

In order to better understand the forming process, a free body diagram was made of the forming zone to be considered analytically. Subsequently, it was compared to the results of the FEM and the ratings of the practical tests. The free body diagram is depicted in Fig. 7

In this model it is assumed that the wire is fixed in the clamping while the pulling is realised by the feed. The necessary force $F_{v}$ for the feed is the same one that acts in the clamping. The curve is generated by the bending moment (top right) and the wire is re-straightened by the second

Fig. 6 Archimedean loop
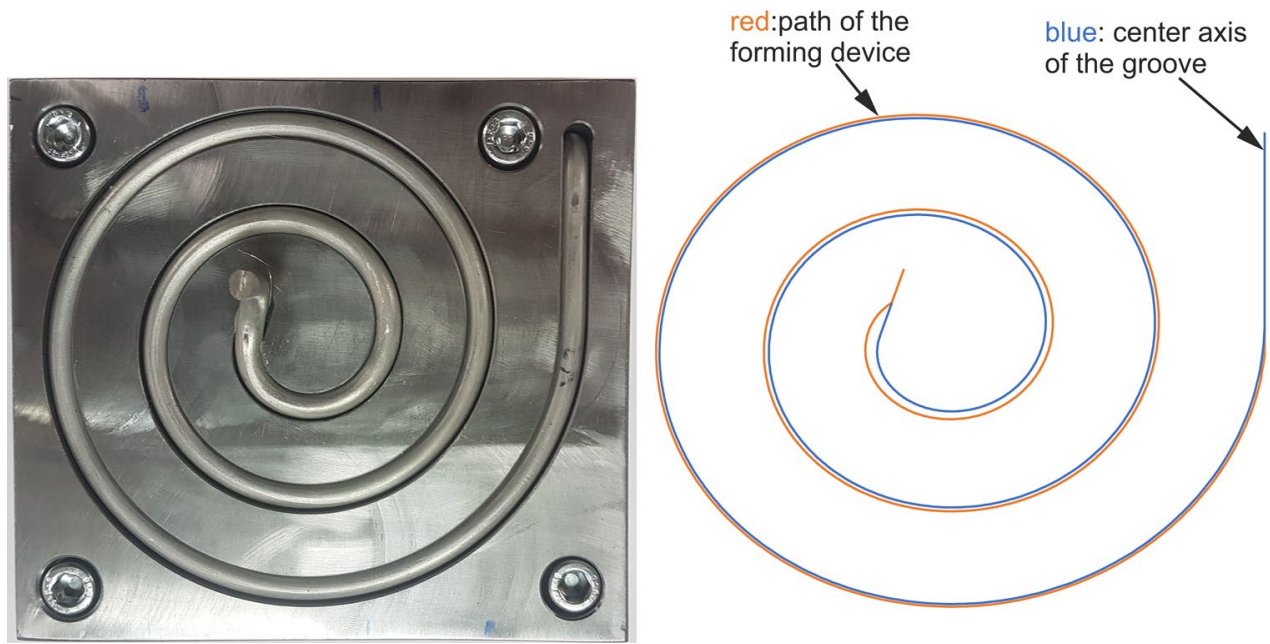


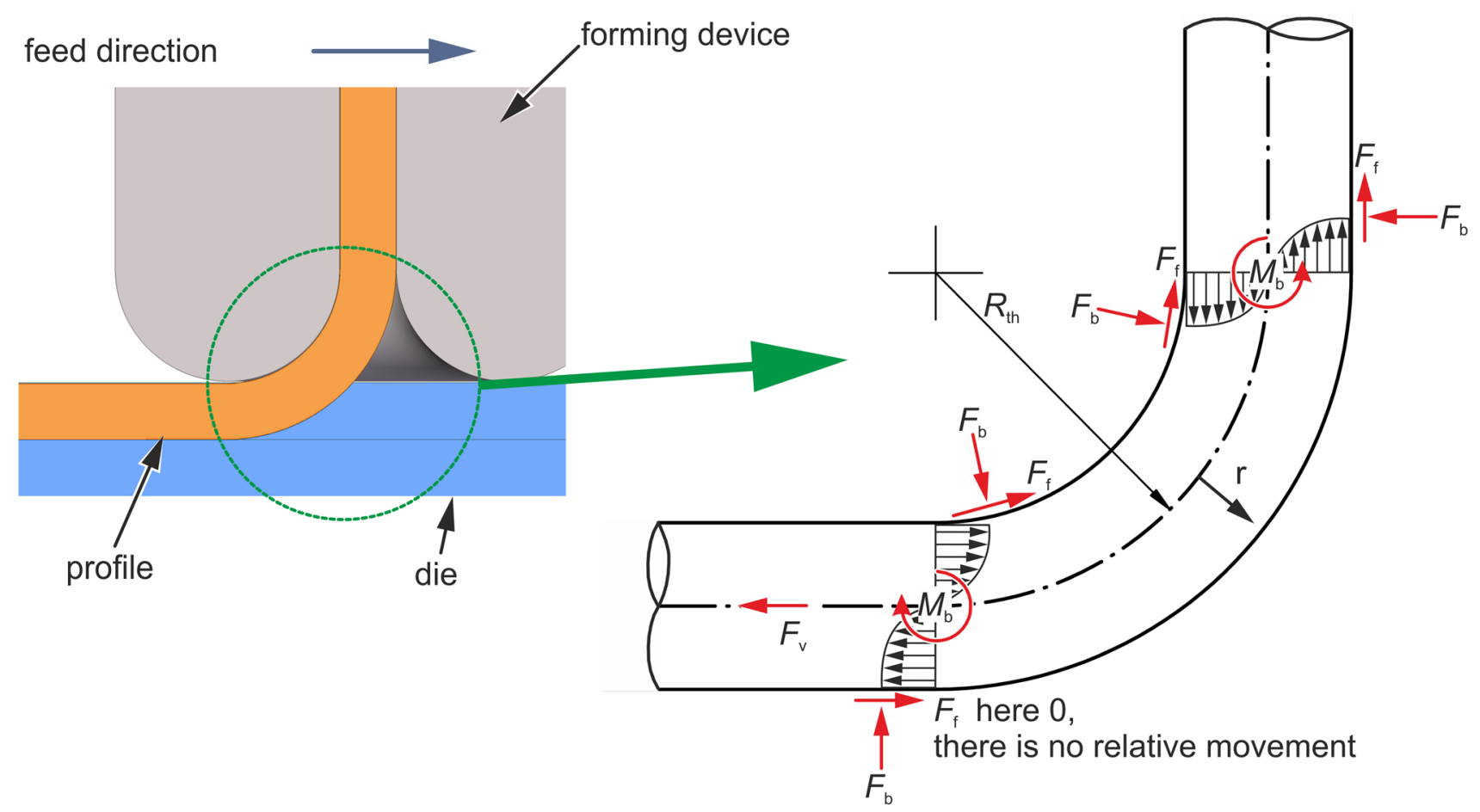

Fig. 7 Forming forces

bending moment (bottom left). During the bending process, the profile is supported by the wire feed and the tool form, whereby the bending forces $F_{b}$ and the resulting frictional forces emerge. Those are summarised in the resulting bending torque $M_{f}$. All this can be calculated by the equilibrium of the moments

$\sum M=0=-F_{v} R_{t h}+2 M_{b}+M_{f}$

Even if the two bending moments rotate against each other here, they must be added together, since both are generated by the feed force. The first bending moment $M_{b}$ is to be determined for the wire, since all other forces can be derived from it. It is assumed that both moments are according to its amount identically. The same applies for the bending forces $F_{b}$. Furthermore, all assumptions are based on the fundamental bending theory. Calculating the bending moment of the elastic zone is neglected, since this zone is small.

First, the stress tensor must be analysed. Here, it is assumed that the stress in the axial-direction is decisively responsible for the deformation of the bending form. Thus, the tensor is reduced as follows:

$\sigma=\left[\begin{array}{rrr}\sigma_{a} & 0 & 0 \\ 0 & 0 & 0 \\ 0 & 0 & 0\end{array}\right]$
The stress $\sigma_{a}$ can be determined from the tensile test using the strains $\epsilon_{a}$. Thus, the strengthening of the material can be also taken into account. It is also assumed that the stress distribution in the wire is symmetrical and the geometric middle plane of the cross section has constant position during process and is at once the neutral plane regarding strain and stress [14]. The strain in the cross section

results from the bending of the wire:

$\epsilon_{a}=\frac{r}{R_{t h}}$

This leads to a logarithmic deformation of

$\varphi_{a}=\ln \left(1+\frac{r}{R_{t h}}\right)$

This enables to calculate the bending moment as follows:

$M_{b}=2 \cdot \int_{0}^{r} \sigma_{a} \cdot r \cdot d A$,

Now the results from the tensile test can be used for the calculation of the stress, in doing so the material model of Ludwik is used applying the approach of Nadai and Reihle

$\left|\sigma_{a}\right|=K_{f}$

$\left|\sigma_{a}\right|=C \cdot \varphi^{n}$ 
The stress in the cross section is set equal to the yield stress from the tensile test. $C$ and $n$ are material-dependent constants:

$C=R_{m}\left(\frac{e}{n}\right)^{n}$

and

$n=\varphi_{g l}$

The area $d A$ is calculated acoording to the following equation:

$d A=b \cdot d r=2 \cdot \sqrt{r_{a}^{2}-r^{2}} \cdot d r$

While $r_{a}$ is the radius of the profile $\left(\frac{D}{2}\right)$, the resulting forces $F_{b}$ can be determined by calculating the bending moment that emerges from support within the die groove.

$M_{b}=2 \cdot F_{b} \cdot r_{a}$

$F_{b}=\frac{M_{b}}{2 \cdot r_{a}}$

The frictional force can be determined at a frictional coefficient $\mu$ at 0.1 .

$F_{f}=F_{b} \cdot \mu$

Since the friction is known, this can be summarised in one frictional torque for convenience only

$M_{f}=2 \cdot\left(F_{f} \cdot R_{i}\right)+F_{f} \cdot R_{a}$,

with

$R_{a}=R_{t h}+r_{a}$

and

$R_{i}=R_{t h}-r_{a}$

The frictional force at the contact surface of the die groove is to be disregarded, since there are no relative motions between the profile and the die. As all torques are known, the feed force can be calculated by the equilibrium of the moments

$\sum M=0=-F_{v} R_{t h}+2 M_{b}+M_{f}$

It must be mentioned that since they all are generated by the feed of the forming device, they are to be set positively. Adapted concerning the feed force this leads to

$F_{v}=\frac{2 M_{b}+M_{f}}{R_{t h}}$.
The analytical observation allows a deeper insight into the forming process. By determining the feed force, the drives or, conversely, the limits for the maximum deformable cross section depending on the material can be designed. If the flow curve is not known, the yield point can be used for calculation, but a material-dependent safety factor must be considered as the yield stress increases with increasing deformation.

The detailed consideration of the friction shows the essential friction points and their share to the overall process. For example, with a friction coefficient $\mu$ of 0.1 , this amounts to approx. $26 \%$ and with a friction coefficient of 0.2 even $41 \%$ of the required feed force. The amount for the bending moment remains constant. This makes clear that the friction in the forming has a significant share and is to be optimised in further developments.

As already mentioned in Sect. 4, Eq. (2), the offset $X$ must be adjusted by a fixed value $X_{c}$ during the path correction. This results from the stiffness of the forming device. The stiffness, in turn, depends on the feed force $F_{v}$. By determining this, the offset $X_{c}$ can now be determined more easily. However, this should be done in the following step.

\section{Experimental validation}

In a next step, the three results (i.e. analytical, FEM, and experimental) can be compared to each other, see Fig. 8. The feed force is represented in relation of the feed position. The course of the path and the points are also marked in the figure.

There can be seen a good agreement with the practical and the FE-model. The setoff in the horizontal axis between the outcome of the FE-model and the experiment results from the larger distance to the feed in the radius area to compensate the stiffness $\left(X_{c}\right)$ of the wire feed, see Fig. 2. The analytical model according to its amount is slightly higher and is only achieved in the peaks, thus the model is suitable for a preliminary design of the driver.

The comparison was made with both the softer AL99.5 and the somewhat more solid EN AW 6060. The agreement

of the three models was identical for both materials. This shows the significance of the analytical approach. In addition, it can be seen that the feed force is mostly a materialdependent variable. After choosing a material, it can only be optimised by an adjustment to the friction. Some tests have shown that the forming speed has no significant impact here. A higher forming speed only leads to a slightly higher starting peak before the value drops to a constant value.

Furthermore, the stress curve was investigated in the cross section of the profile. However, only the FEM and the analytical model could be compared to each other. For this comparison, the axial tensions $\sigma_{a}$ in a varying local coordinate system 
Fig. 8 Comparison of the different models (EN AW 6060)

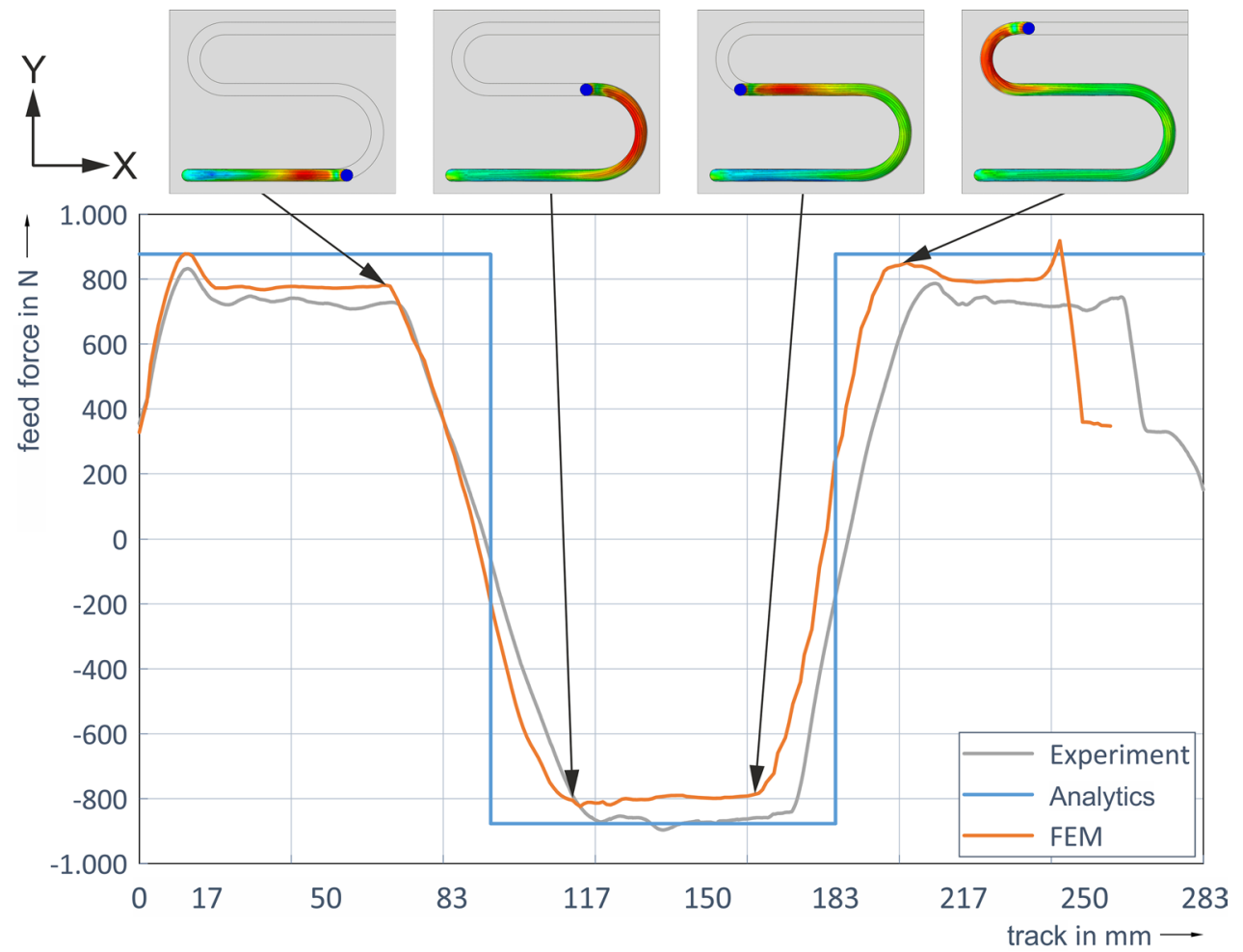

along the cross section of both bending areas were evaluated, see Fig. 9. There can be seen a concordance with the draw area of the profile. The tension curves correspond with each other, but there is a slight deviation at the edge of the inside curve that is due to the friction between the profile and forming device.

On the left side of the analytical model the superposition by the feed force is taken into account. This leads to a positive correspondence in the draw area, but the displacement of the neutral axis is larger than in the analytical model. Furthermore, the influence of the contact to the tool surface in the pressure area (inside curve) can be remarked.

Figure 10 shows the plastic strain in axial direction at the same positions as in Fig. 9. When entering the forming zone (right), you can see a good match between the FEM and the analytics. The deviation at the edge can be explained by the material hardening. In the exiting area of the forming zone both curves are constant (left), a clear offset between the two curves can be seen. This offset occurs due to the two bending processes that the wire passes through. It is difficult to be captured analytically. It also explains the offset between the two models in Fig. 9 on the left side. In addition, a permanent strain of the wire of 4-5\% indicates a cross-sectional reduction and an extension of the wire, which could be observed in the practical experiments.
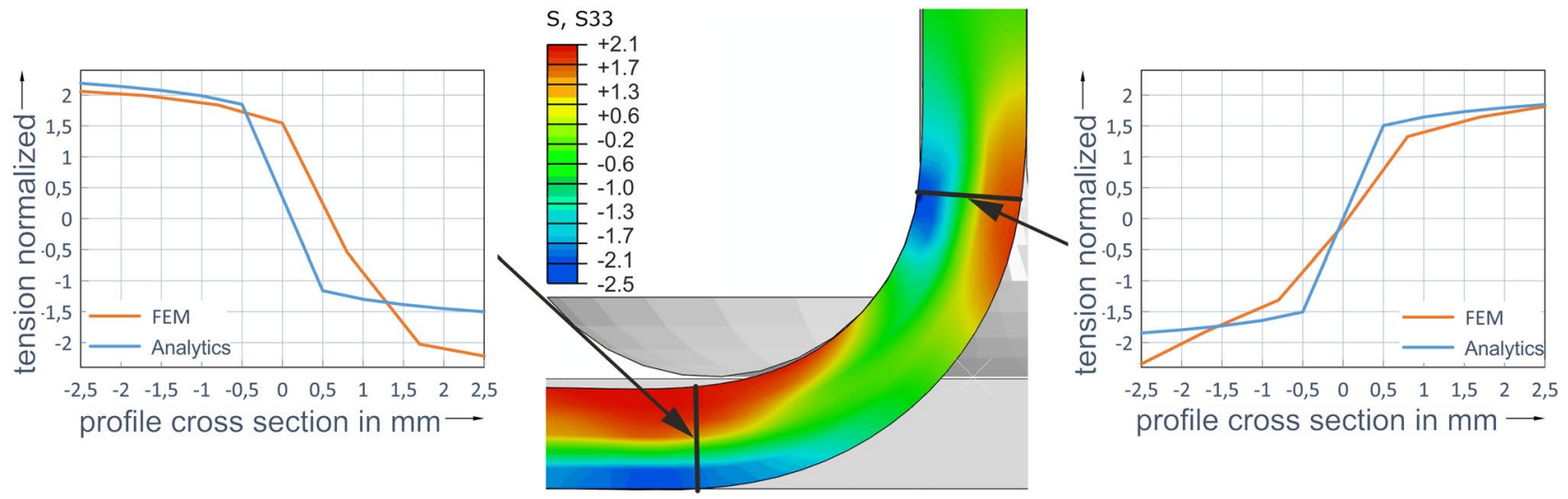

Fig. 9 Tension $\sigma_{a}$ in axial direction, normalised $\frac{\sigma}{K_{f 0}}$ 


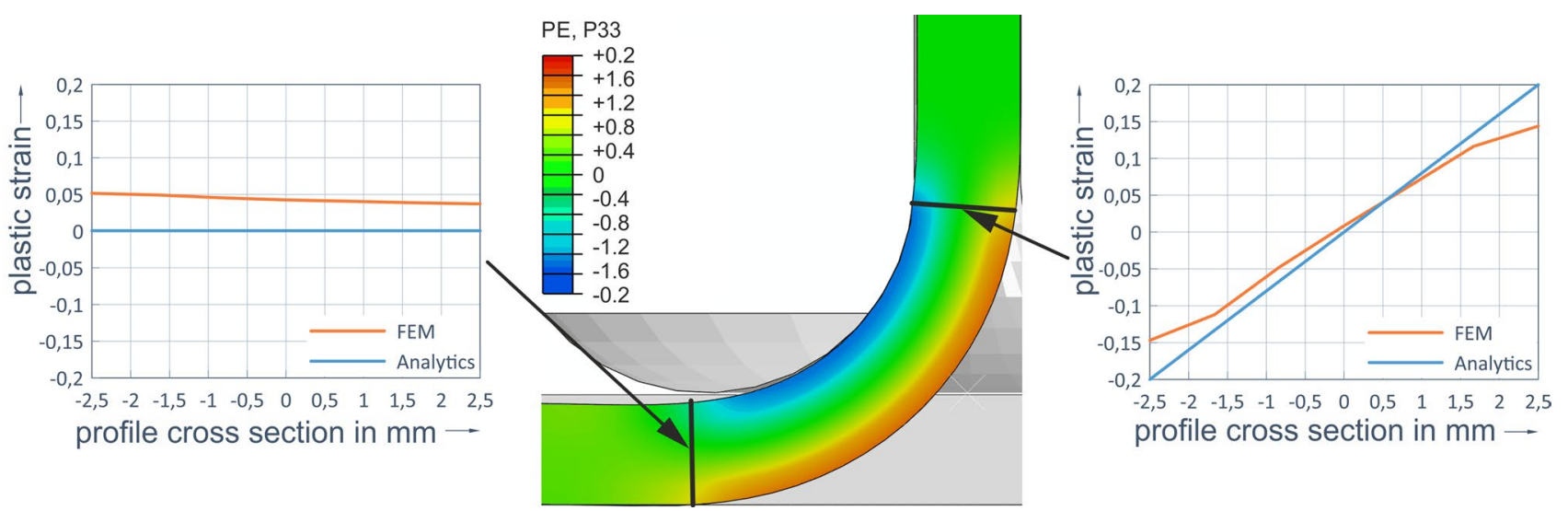

Fig. 10 Plastic strain in axial direction

Finally, it can be said that although the models examined here do not always have $100 \%$ agreement, this has made things clearer: The permanent plastic strain has stretched the wire and was slightly reduced in the cross section, resulting in a slight deviation between the calculated and the measured feed force. However, this deviation is so small that it can be neglected in most cases.

\section{Conclusion and outlook}

The incremental die bending is an innovative bending procedure that has advantages over the established procedures. There can be created geometries that won't be conceivable with common bending procedures. Due to the die bound forming process, the profile is supported which improves the precision and quality. Due to the support errors in the bending angle, the long limbs are not that vigorous like for example in the rotary draw bending, since the profile is supported during the entire process and not only in the bending area.

Since the position of the forming zone does not comply with the central axis of the wire feed, the setoff is to be taken into account in the planning of the path kinematics. There was depicted a model for calculating the setoff and there was developed a tool for implementing this compensation automated so that various paths can be programmed quick and easily. The tool is designed for two-dimensional processes. The extension for three-dimensional geometries is already in progress.

Fig. 11 Profile feed unit

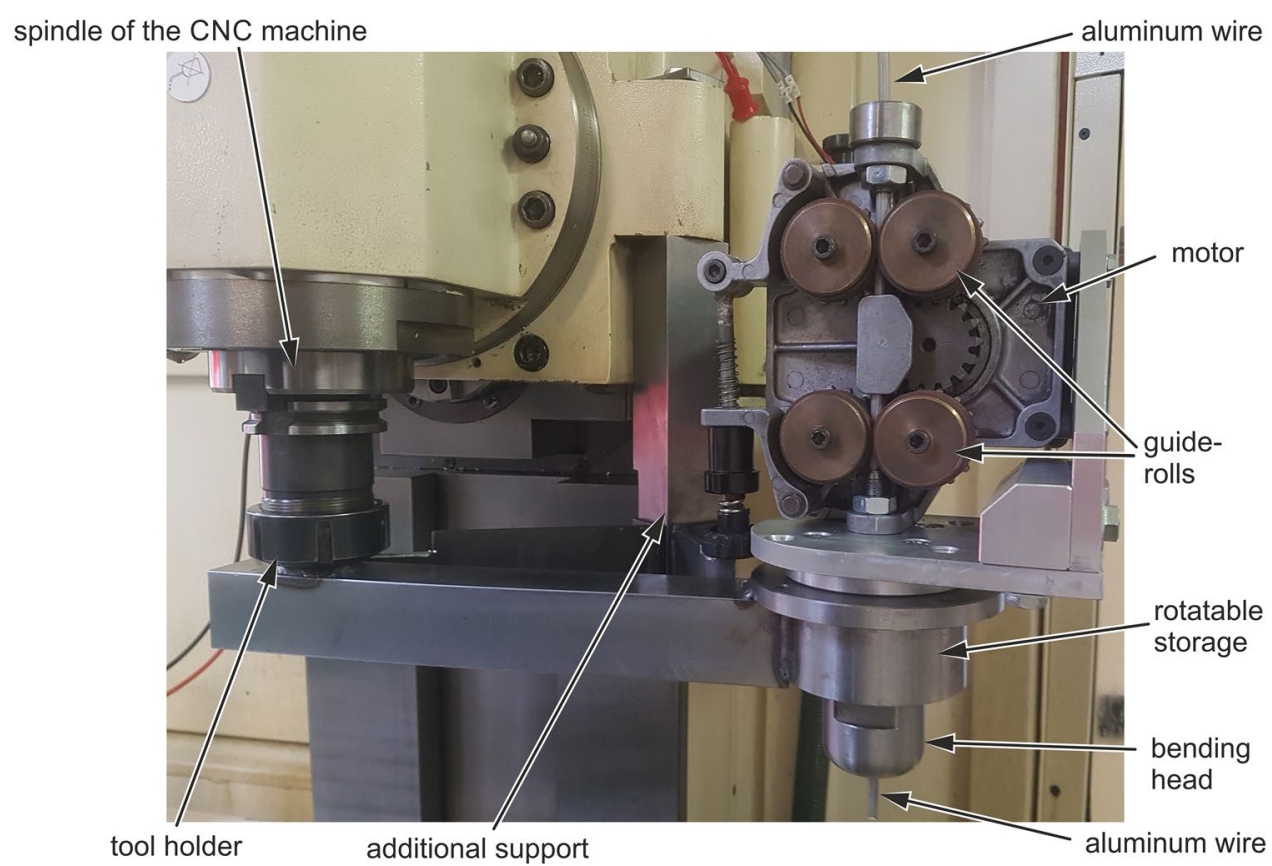


An analytical approach for the interpretation of the process forces was presented, which could be confirmed by the FEM and the experiments.

Thus, the approach is ideal for understanding the forming process and designing the drives for the process. In addition, it can also determine the loss caused by the friction.

Furthermore, the stress flow in the cross section was examined more closely. This revealed and explained some of the reasons for the discrepancies between the models.

The stress superposition is the most common method for the springback compensation but it cannot be applied in all bending processes. In case of incremental die bending, this can be realised by breaking via the feed driver of the profile. In the next step there should be caused an aimed tension superposition. For this purpose, future work concentrated on a wire feed system, see Fig. 11, which enables the feed of an endless wire and which allows a stress superposition. Furthermore, the radius area shall be investigated analytically, since here the forming by torsion is superposed.

Acknowledgements Open Access funding provided by Projekt DEAL.

Open Access This article is licensed under a Creative Commons Attribution 4.0 International License, which permits use, sharing, adaptation, distribution and reproduction in any medium or format, as long as you give appropriate credit to the original author(s) and the source, provide a link to the Creative Commons licence, and indicate if changes were made. The images or other third party material in this article are included in the article's Creative Commons licence, unless indicated otherwise in a credit line to the material. If material is not included in the article's Creative Commons licence and your intended use is not permitted by statutory regulation or exceeds the permitted use, you will need to obtain permission directly from the copyright holder. To view a copy of this licence, visit http://creativecommons.org/licenses/by/4.0/.

\section{References}

1. Gerlach C (2010) Ein Beitrag zur Herstellung definierter Freiformbiegegeometrien bei Rohren und Profilen, Dissertation, Universität Siegen, Shaker Verlag
2. He Y, Heng H, Zhiyong Z, Mei Z, Jing L, Guangjun L (2011) Advances and trends on tube bending forming technologies. Chin J Aeronaut 25:1-12

3. He Y, Jing Y, Mei Z, Heng L, Yongle K (2009) 3D numerical study on wrinkling characteristics in NC bending of aluminum alloy thin-walled tubes with large diameters under multi-die constraints. Comput Mater Sci 45:1052-1067F

4. Engel B, Gerlach C, Cordes S (2008) Biegemomentenabschätzung des Dornbiegeverfahrens, Whitepaper. http://www.utfscience.de

5. Gu Z, Lü M, Li X, Xu H (2016) Stretch bending of Z-section stainless steel profile. J Iron Steel Res 23(6):525-530

6. Liu T, Wang Y, Wu J, Xia X, Wang J, Wang W, Wang S, Wang S (2015) Springback analysis of $Z$ and T-section 2196-T8511 and 2099-T83 Al-Li alloys extrusions in displacement controlled cold stretch bending. J Mater Process Technol 225:295-309

7. Zhao J, Zhai R, Qian Z, Ma R (2013) A study on springback of profile plane stretch-bending in the loading method of pretension and moment. Int J Mech Sci 75:45-54

8. Deng T, Li D, Li X, Ding P, Zhao K (2014) Hot stretch bending and creep forming of titanium alloy profile. Proc Eng 81:1792-1798

9. Sprenger A (1999) Adaptives Streckbiegen von Aluminium Strangpressprofilen, Dissertation, Universität Erlangen, Meisenbachverlag

10. Murata M, Aoki Y (1999) Analysis of circular tube bending by MOS bending method. In: Altan T (ed) Advanced technology of plasticity, vol I, 1996, pp 505-508

11. Hermes M, Kleiner M (2007) Verfahren und Vorrichtung zum Profilbiegen/An apparatus for bending profile DE 102007013 902 A1

12. Neugebauer R, Drossel WG, Lorenz U, Luetz N (2002) Hexabend-a new concept for 3D-free-form bending of tubes and profiles to preform hydroforming parts and endform space-framecomponents. Adv Technol Plast 2:1465-1470

13. Hermes M, Staupendahl D, Tekkaya AE (2014) Verfahren und Vorrichtung zur inkrementellen Herstellung von gebogenen Drähten, Rohren, Profilen oder dgl. aus stangenförmigen metallischen Materialien, WO2015144103A1

14. Hosford WF, Caddell RM (1983) Metal forming: mechanics and matallurgy. Prentice-Hall International Inc, Upper Saddle River

Publisher's Note Springer Nature remains neutral with regard tojurisdictional claims in published maps and institutional affiliations. 